\title{
¿Qué quiere decir comunidad? 1
}

Rafael Bautista S.

Centro Cultural Indígena Wayna Tambo

\begin{abstract}
Referring to a time of a reconfiguration of one's own horizon, this paper aims to show in methodological terms the limitations of modern politics in understanding indigenous knowledge and theorizations that bring into the language of politics the notion of "living in community" as the mode of existence of a life-world specific to indigenous cultures. This is a world that, constituted around links of solidarity and reciprocity, has the capacity to make of human existence a place of "merit and responsibility" that properly interprets the sense of the ayllu: the community. Understanding the rationality behind this way-of-life which generates the singularity of the ayllu and producing a theorization of the indigenous concept of "community" is the objective of this work.
\end{abstract}

\footnotetext{
${ }^{1}$ Este trabajo es una versión abreviada del capítulo que con el mismo nombre apareció en La descolonización de la política. Introducción a una política comunitaria de la vida (2012). Las discusiones aquí abordadas fueron expuestas en el Taller sobre teoría política latinoamericana: la primera teoría de la descolonización, que tuvo lugar en la Universidad de Pittsburgh, en mayo de 2012.
} 


\section{Keywords}

ayllu, community, community of relatives, logics of belonging, logics of property, modern society/archaic community, politics of communal responsibility

\section{Resumen}

Referido a un momento de reconstitución del horizonte propio, este trabajo quiere mostrar en términos metodológicos los desencuentros de la política moderna con teorizaciones y conocimientos indígenas que incorporan en el lenguaje de la política sentidos desde los cuales se comprende un "vivir en comunidad" como el modo de existir de un mundode-la-vida específico a las culturas indígenas. Se trata de un mundo constituido en torno a relaciones recíprocas y solidarias que hacen de la existencia un lugar de "merecimiento y responsabilidad" que interpreta apropiadamente el sentido del ayllu: la comunidad. Comprender la racionalidad de ese modo-de-vida que genera la singularidad del ayllu y producir una teorización del concepto indígena de "comunidad", es el objetivo de este trabajo.

\section{Palabras claves}

ayllu, comunidad, comunidad de parientes, lógica de la pertenencia, lógica de la propiedad, política de responsabilidad comunitaria, sociedad moderna/comunidad arcaica

\section{La noción de comunidad}

La noción usual de comunidad convoca una variedad de ideas, lo cual produce una ambigüedad que, literalmente, arrastra su comprensión; de ese modo, es capaz tanto de enarbolar movimientos de liberación como sistemas de dominación. ${ }^{2}$ Es importante recordar que su elaboración en la tradición

2 La "comunidad política" es también un concepto que legitima la soberanía política del Estado de derecho. En este sentido, "comunidad" es un ente abstracto que quiere designar el conjunto de la sociedad civil. La "comunidad cristiana" constituía, en sus inicios, un movimiento de liberación frente al imperio 
moderno-occidental es producida por la cristiandad latina. La comunidad de la iglesia era, como postulado, la adopción existencial del modo de vida de los primeros apóstoles; algo que se retrata en el libro de los Hechos de los Apóstoles: "Perseveraban en oír la enseñanza de los apóstoles y en la unión, en la fracción del pan y en la oración [...]; y todos los que creían vivían unidos, teniendo todos sus bienes en común; pues vendían sus posesiones y haciendas y las distribuían entre todos según las necesidades de cada uno" (Hechos 2:42-45. Cursivas mías).

El comercio de esta palabra sufre muchas transformaciones, ${ }^{3}$ pero conserva siempre algo del ideal manifiesto en aquel modo de vida. Ese

romano. Actualmente, se opone al sistema político vigente un regreso a la comunidad que ya no coincide con el concepto de "comunidad política" estándar, sino con un más allá de la sociedad moderno-liberal-colonial. Esta aparente contradicción en los términos no es contradictoria, más bien expresa el modo peculiar de la estructura moderno-colonial del poder, que "presenta una situación en apariencia paradójica: Estados independientes y sociedades coloniales. La paradoja es sólo parcial o superficial..." [Quijano 2000, 234]. Supuestamente, la forma "sociedad" (moderna) sería un momento superior -en el desarrollo lineal de una historia unívoca (eurocéntrica) - a la "arcaica" forma de comunidad. Al respecto, ver Habermas, Teoría de la acción comunicativa, vol. II). En los hechos, la forma "sociedad" no ha demostrado ser superior a toda otra forma de comunidad sino que, más bien, está demostrando, de modo apresurado, cómo es posible la descomposición paulatina de las relaciones humanas. La "sociedad", de manera general, es la reunión jurídica de intereses individuales; la predominancia exagerada del individuo es lo que especifica el modo "sociedad" y ésta es, precisamente, la razón de la descomposición paulatina de este conjunto: al primar los intereses individuales se sacrifica aquello que se denomina "bien común"; el conflicto se hace inevitable, por eso la política moderna disuelve la legitimidad en la legalidad establecida y, mediante ella, termina atentando contra toda legitimidad posible; pues si la legitimidad radica en la ley, entonces, el pueblo está de más: la política se vacía de todo contenido real, se vuelve inevitablemente formal. Una de las primeras críticas contundentes a la forma "sociedad" se puede encontrar en la diferencia explícita que hace Marx entre Gesellschaft y Gemeinschaft (Dussel 1988, 1990 y 2008). De modo que, en el sentido que queremos formular, comunidad no es nunca sinónimo de "sociedad".

${ }^{3}$ No pretendemos aquí elaborar una historia de la palabra (lo cual excede los límites de este trabajo). Pero cabe destacar que la latinización de la palabra no coincide con el sentido anteriormente expuesto; lo mismo puede decirse de su comprensión helenizada. Parece que esta no-correspondencia se pretendió superar desde temprano, en detrimento del sentido original (cultural y antropológico) hebreo-semita. Porque, por ejemplo, el latín communitas, que mienta el estado común, proviene de communis, y éste de moenia, que hace referencia a las murallas, es decir, a la idea de defensa común; munus, por su parte, dice al oficio o cargo, que implica la noción de obligación. Se podría decir que común es lo que pertenece a muchos, por esto es común. De similar modo, 
contenido es el que destaca la analogía que se quiere mostrar y sugiere una apropiación de la palabra (apropiación lingüística del vencido, que quiere expresar en el lenguaje del dominador su situación real y su pretensión de liberación, además de su propia cosmovisión), en gran parte de las rebeliones indígenas, sobre todo desde el siglo XVIII. Es decir, en términos políticos, no tendríamos por qué renunciar al término comunidad (por ser occidental), que fue también usado durante las rebeliones indígenas, como muestra no sólo de estrategia política sino también de apropiación desprejuiciada que hace el indio del lenguaje hegemónico. Si el contenido liberador de la comunidad -que se quiere proponer - es trascendental, y no sólo particular, entonces el discurso también debe proponerse su universalización, apropiándose de conceptos fundamentales para dotarles de aquel contenido que queremos expresar. ${ }^{4}$

Parece que esos contenidos son ya manejados en las rebeliones de Tupac Amaru y Tupac Catari, para incorporar esta palabra en el lenguaje político de estas luchas y depositar en ella el sentido desde el cual se comprende

los presocráticos (en los albores de la filosofía griega), aluden a lo común, como principio o arkhé, a lo Uno (aquello que explica y da razón de la multiplicidad). Heráclito dirá que el logos es lo común, como patrimonio de todos, como manifestación de lo verdadero: lo divino. En general, para los griegos, la ley es lo común, el orden que impone la physis, o naturaleza, como orden divino. Por eso se dice lo común, como un orden impersonal que le impone al ser humano un orden trágico y necesario. Por eso el humanismo griego no pudo producir un concepto positivo de libertad, menos de liberación; producción que será posible, en Occidente, gracias al humanismo semita, contenido en el cristianismo (Dussel 1969, 1975). La noción de comunidad que fue adoptada por los movimientos indígenas de liberación en el Nuevo Mundo proviene de aquel contenido presente (de modo ambiguo) en el cristianismo. Lo cual demuestra que, del lado indígena, hubo ya anticipadamente una razón crítica capaz de asumir lo mejor y más notable de Occidente, de modo crítico, y no como mera apropiación inconsciente.

${ }^{4}$ Sólo el que está lleno de prejuicios ve en todo lo ajeno lo incompatible y, en consecuencia, imposible de complementariedad. Curiosamente la lógica aymara no concibe una resolución del conflicto por la anulación de uno de sus polos. Cuando aparece un fundamentalismo indigenista, que sólo sabe proponerse la romántica admiración estática de lo que se es, de modo involutivo, inevitablemente afirma una política conservadora, también de dominación. Pero este tipo de apuestas riñen con la propia cosmovisión comunitaria de la vida. Tal vez por eso estas posturas parecen más provenir de ámbitos mestizos que de verdaderamente indígenas. 
un vivir en comunidad, como el vivir propio del ayllu ${ }^{5}$ o el modo-de-vida anterior a la "llegada de los europeos", en el lenguaje castellano. ${ }^{6}$ Ese contenido implícito, el que se estaría expresando en la recurrencia de señalar lo comunitario, en tanto el modo-de-existir de este mundo-de-la-vida específico (el "andino"), ${ }^{7}$ sería el del ayllu. Es lo que se pretendería expresar

${ }^{5}$ Concepto fundamental que iremos trabajando a lo largo de este trabajo. Deseamos aclarar, de antemano, que no nos interesa tanto la noción usualmente manejada, como descripción empírica de organización social, como la que elabora Bautista Saavedra en El ayllu (1903): como un conjunto de familias repartidas de modo agrupado. Reducción sociológica repetida, curiosamente, por una variedad de intelectuales indígenas en la actualidad, haciendo imposible una consideración, si se quiere, filosófica, del asunto. Nuestra intención será escarbar, precisamente, esa posibilidad.

${ }^{6}$ Al parecer, la traducción de ayllu o modo-de-vida anterior a la llegada de los "intrusos europeos", es ya depositada en la palabra comunidad, a propósito de las diligencias que realiza Tupac Amaru, en favor de los indios, previas a su alzamiento armado (Lewin).

${ }^{7}$ Resulta curioso que la afirmación de una identidad (la 'andina') no pase por una consideración crítica del término que bautiza tal identidad. Dentro de la tradición humanista occidental, nombrar algo es darle el ser (cuya procedencia, casi siempre olvidada, es la cultura hebrea que, vía cristianismo, penetra en la cristiandad occidental y en la posterior modernidad). Pues bien, ¿de dónde procede la palabra 'andes'? Casi todos concuerdan en que la violencia occidental empieza con el bautizo que se hace de tierras que ya tenían un nombre propio (negada la humanidad de los habitantes, también se niega su mundo, negando los nombres que tenían sus tierras); pero nadie pone en entredicho el nombre ('andino') que designa y agrupa a las culturas quechua, aymara, a Tiahuanaco, etc. Curiosamente, Virgilio, uno de los autores predilectos del Renacimiento (sobre todo por la Eneida), nació en 'Andes', un pueblo en la región de Lombardía, cerca de Mantua; desde esta región se puede apreciar, al noreste los Alpes, y al suroeste los Apeninos (como en los 'Andes' se ve la cordillera occidental y la oriental). Puede que algún cronista 'letrado' haya querido rendir un homenaje a Virgilio, bautizando con el nombre de su pueblo la región que hoy conocemos como 'Andes'. Lo curioso es que los indigenistas adopten este nombre después (en-cubriendo otra vez lo que ya habían encubierto los españoles). No es nada improbable que este sea el origen de 'Andes', 'andino' y, en todo caso, la no clarificación de este origen, huelga decir, da muestras de una reprochable falta de criticidad a la hora de sostener empecinadamente una afirmación cultural que, en principio, acepta de manera irreflexiva un nombre que le fue impuesto (Bautista S. Rafael 2006). Una versión bastante extendida indica que esta denominación procede del "Antisuyo", o región de las cordilleras; pero, aun así, ni el "Antisuyo" comprende todo el mundo "andino", que sería, en todo caso, todo el "Tahuantinsuyo", ni abarca siquiera el "Kollasuyo"; es decir, el "antis" del "Antisuyo", indica una región de los cuatro "suyos" y no la totalidad que se pretende expresar con "lo andino". 
con esta noción, depositando este contenido en una palabra que expresa, ${ }^{8}$ aunque de distinto modo, ese conjunto de relaciones recíprocas y solidarias que hacen de la existencia un lugar de merecimiento y responsabilidad; es lo que más se acercaría, semánticamente, al sentido original de ayllu: la comunidad.

La noción es todavía una idea. Más allá de la concepción acostumbrada de comunidad (cargada de toda la ambigüedad referida), deseamos explicitar los contenidos implícitos que guarda la noción en su sentido específicamente indígena. Entonces, se trata de la producción misma del concepto. Dotar de contenido a algo todavía vago y ambiguo. Producción que tiene que ver con el volver autoconsciente la racionalidad presupuesta en este nuestro modo-devida concreto; es decir, producir el concepto significa, en definitiva, producir nuestra propia subjetividad. Pero no se trata de inventarnos algo sino de hacer consciente lo que contenemos siempre (inclusive aunque fuera de modo negado): tomar ya no sólo conciencia sino pasar a la autoconsciencia del sentido que nos presupone como parte responsable de una comunidadde-vida. Adquirir autoconsciencia de ese sentido es, en última instancia, producir la autoconsciencia de lo que somos.

\section{El concepto}

En el concepto se expresa y se formaliza un modo-de-vida y su producción es también la producción y el desarrollo de ese modo-de-vida. Esto quiere decir que la producción del concepto, como producción de conocimiento, no es un lujo superfluo de afanes especulativos, sino el lugar desde donde los compromisos políticos se hacen explícitos. El conocimiento de uno mismo tiene consecuencias siempre, en última instancia, políticas; porque en éste se juega la vida una subjetividad en proceso de reconstitución,

\footnotetext{
${ }^{8}$ La tarea del pensar es también sacar a las palabras de su ámbito cotidiano y llevarlas a un ámbito fundamental; aquello que insinúan, aunque de modo ambiguo. Lo que se indaga es el contenido. Este indagar es la historia de la producción del concepto. Por eso el pensar que insistimos es un pensar que piensa lo que está pensado. Por eso, también, es un pensar epistemológico, porque pensando vacía el contenido previo del concepto para dotarle un nuevo contenido; por ejemplo: así como los griegos pensaron la helenidad y a esa abstracción llamaron filosofía, así la tarea de una filosofía boliviana será la de pensar su propio mundo-de-la-vida.
} 
cuyo proyecto de vida no puede sino determinarse como la propia autodeterminación del sujeto.

Hegel es quien advierte, de modo lúcido, esta finalidad última de la ciencia: la producción de la subjetividad. ${ }^{9}$ De tal modo que la praxis teórica (en cuanto filosofía) no es o no debiera ser un pasatiempo especulativo del ocio sino, y es el caso de Hegel, un requerimiento fundamental de todo proyecto político. La doctrina del concepto es, y no por casualidad, la última parte de la Ciencia de la lógica; se podría decir que es la culminación de todo el proceso lógico de constitución de la ciencia, es decir, de la subjetividad, donde se afirma el horizonte último que da consistencia a una subjetividad que ve en su despliegue de dominación global, una teodicea, un destino manifiesto de lo Absoluto. Escribe Hegel: "Ser y esencia, por lo tanto, son los momentos de su devenir; pero él [el concepto] es la base y verdad de ellos [...], el concepto es la siguiente absoluta unidad del ser y de la reflexión, que el ser en-sí y por-sí existe ante todo porque es también reflexión o ser-puesto, y que el ser-puesto es el ser en-sí y por-sí [...]. Esta infinita reflexión en sí misma, es decir, que el ser en-sí y por-sí existe sólo porque es un ser-puesto, es el completarse de la sustancia. Pero este completarse no es más la sustancia misma, sino algo más elevado, esto es, el concepto, el sujeto" (Hegel 511-513).

Ese completarse es el Dios hecho hombre; aquella infinita reflexión produce la historia como su exteriorización que, en su devenir, acontece ese completarse que ya no es más la sustancia inicial sino, y lo subraya, el sujeto. No podía estar mejor expresado el eurocentrismo en su fundamentación ontológica. El sujeto moderno-europeo (ahora norteamericano) lo es todo, el Absoluto que se completa en su devenir; el resto del mundo es apenas el teatro de este su devenir en su completitud (por eso para la subjetividad moderna, el mundo le aparece apenas como el conjunto de mediaciones para la realización plena de su proyecto acabado de dominación).

Más allá de Hegel, en nuestro caso, la conciencia no parte de la conciencia sensible sino del acontecimiento. La subjetividad que se libera no se enfrenta a los entes sino a la historia, a su historia. Aparece ante sí desde la

\footnotetext{
${ }^{9}$ Pero en Hegel se trata de la producción de la subjetividad moderna; por esto, las consecuencias que deriva de ello, es decir, la absolutización del sujeto moderno europeo y la preeminencia de lo lógico en desmedro de lo histórico, es algo que no podemos dejar de criticar. He desarrollado esta discusión primero en Octubre: el lado oscuro de la luna (2006) y posteriormente en Pensar Bolivia bajo el cielo de octubre, de próxima aparición.
} 
interpelación de su ser histórico. Por eso, la producción del concepto será de modo hermenéutico. La hermenéutica nos hace posible el configurar el existir como posibilidad misma del "entenderse y de ser ese entender" (Heidegger 33). En este sentido, el interpretar hermenéutico es el desde-donde se hace inteligible el "modo de ser" del existir: "la interpretación es algo cuyo ser es el del propio vivir fáctico".

En ese sentido, la producción del concepto no es un añadido, desde fuera, sino que sugiere, en este caso, un reconstituir del existir según sus propias posibilidades; el cómo de este existir es como el despertar del existir mismo, hacer consciente el cómo del existir es hacer consciente su desdedonde; el concepto "muestra el haber previo", por eso: "Los conceptos fundamentales no son añadidos posteriores, sino motivos conductores: tienen a su manera el existir en sus manos" (Heidegger 35).

Ahora bien, la posición o situación hermenéutica es siempre nuestra situación de comprendido dentro del mundo-de-la-vida que presupone el existir, por ello no se trata de un cotejar autores o teorías sino de un explicitar hermenéuticamente una comprensión que ya nos presupone y da sentido a la revolución que nos está aconteciendo $0^{10}$ y está dando lugar a una transformación profunda de esta entidad abstracta llamada Bolivia. Una entidad formal que nunca pudo adquirir contenido porque siempre negó la realidad de la cual emergía y a la cual se debía. La posibilidad de, por vez primera, constituir la nación y trans-formar un Estado colonial, se hace real cuando acontece el des-cubrir lo que somos y lo que nos constituye como humanidad. Por eso se trata de un producir que nos produce; el reconocimiento de aquello que nos sostiene y desde donde hacemos posible una "revolución democrático-cultural". Ése es el desde donde se abre nuestra situación hermenéutica que, al ir produciendo el concepto, va reconstruyendo el horizonte de sentido que presupone nuestro existir.

Para desarrollar de modo organizado este interpretar hermenéutico y para tomar, como se dice, atajos en nuestro camino, recurriremos a algunos

${ }^{10}$ En sentido estricto: no preguntamos a libros o autores sino al mundo-de-la-vida (en este caso, el llamado andino) de modo sistemático; es decir, por reflexión, nosotros mismos aparecemos como los interrogados, porque provenimos de aquello que, de modo implícito, se encuentra presente, aunque sea por ausencia o negación, en nuestro propio modo cotidiano de existir. El hecho mismo de ch'allar, de esperar a los muertos o bailar danzas autóctonas ya expone una estructura del existir que se re-conoce en esas manifestaciones como propias. 
trabajos de Grimaldo Rengifo que señalan las aproximaciones pertinentes, para nuestros fines, de lo que iremos desarrollando en perspectiva política. No se tratará, en todo caso, de una "lectura correcta" de aquello (no se trata de remitirse al texto), sino del desarrollo, en el sentido que proponemos (de una hermenéutica de la exposición del sujeto, que siempre somos, en todo caso, nosotros mismos, como parte de este mundo-de-la-vida nuestro), de lo sugerido, en un tratamiento que potenciará el contenido político del concepto.

Tampoco nuestro interés se concentrará en responder con "exactitud" a alguna definición que se haya producido, sobre todo por el discurso llamado "indigenista". ${ }^{11}$ En este sentido la producción del concepto ha de tener, inevitablemente, por motivos ya señalados, el desarrollo de su contenido político; la noción todavía abstracta de comunidad la iremos desarrollando como una producción del concepto que comprime al sujeto de esa exposición (la lógica y estructura de la comunidad la expresa el sujeto mismo),

${ }^{11}$ Creemos que una considerable literatura indigenista, reproduce, inconscientemente, el marco categorial moderno-occidental. Esto es lo que imposibilita un conocimiento potencial y produce un adecuarse a lo ya definido y comprendido, un repetir lo ya sabido. Por ejemplo, si se dice que: "la certeza de lo divino es la intuición de la totalidad" y luego, que este divino, es la "interrelación íntima del ser absoluto de la totalidad con respecto al estar de la vida" (Miranda Luizaga y Del Carpio 23); inadvertidamente se está reproduciendo no sólo la cosmovisión helénica, sino el fundamento de una ontología de la dominación. En efecto, el ser es el fundamento ontológico de una totalidad absoluta y es, precisamente, la categoría fundamental que estructura lo que es, lo dado, como sistema cerrado, como totalidad truncada. Por otro lado, la insistencia empírico-contrastable de los estudios históricos y antropológicos, por ejemplo, del ayllu, ha derivado en su des-potenciamiento; pues no otra cosa significa cierto afán positivista (bastante común en estos antropólogos e historiadores) de cotejar sólo su aparecer "objetivo", el cual es ya un refrendar el encubrimiento inicial, pues lo constatable es también producto de la distorsión histórica que se produjo desde, sobre todo, las reducciones toledanas. También, el énfasis politicista, abundante en la actualidad, adolece no sólo de una epistemología crítica sino hasta de una lógica: por ejemplo, cuando Patzi critica el apelar al "romanticismo étnico ancestral", como el apelar "al ayllu ancestral como una nueva forma de organización, pero (no) en modo contemporáneo" (Patzi 236), su crítica no sabe reconocer niveles del discurso, pues esa referencia (del ayllu ancestral) se la debería estudiar al nivel de los postulados y no de la empiria; la misma crítica puede hacérsele de modo inverso, pues lo que demanda acaba siendo un enunciado más, sin otra indicación que la enunciación misma: "no lograron construir un proyecto societal alternativo al sistema de capital y la política liberal, que supere el etnocentrismo indígena y el localismo agrario" (Patzi 236). Si ese proyecto societal alternativo debe ser la superación del etnocentrismo indígena, entonces no se entiende su segunda demanda: "la estructura organizativa del partido no obedecía a las estructuras comunitarias" (Patzi 236). 
de modo que se explicite el carácter político de potenciamiento del sujeto que se expresa en el concepto. La producción del concepto trata de algo más que su mera resignificación semántica. De ese modo, lo sugerido nos ayuda a exponer la fidelidad, no del sentido original de lo sugerido, sino la fidelidad encaminada por la hermenéutica del existir mismo.

\section{La comunidad de parientes}

Todavía, en términos abstractos, comunidad indica una suma de relaciones recíprocas. El cómo y el qué de éstas señalan el modo-de-ser, pero nuestra aproximación quiere ir más acá: indagar el por qué. En términos de ser se postula algo dado, pero lo que aparece no es precisamente algo dado sino algo cuya referencia no se agota en la determinación fija y limitada de sus elementos.

La especificación inmediata que aparece como comunidad, en términos de ayllu, indica una comunidad de parientes. No se trata de lo común abstracto de la tradición occidental, como un orden trascendental más allá de lo humano. La determinación de parientes, ya expone el sentido de reciprocidad que se quiere indicar. Lo concreto aquí es el modo de relación: la comunidad de parientes es un modo de relación que establece la propia existencia. El ayllu indica no una comunidad a secas, sino la congregación siempre extensiva de parientes potenciales; de modo que la comunidad, por principio, se determina como una comunidad abierta: "En un mundo de equivalentes y donde la noción de persona es vivida como un atributo de todo cuanto existe y no sólo adjudicable a los miembros de la comunidad humana, la palabra "parientes" es extensiva también a los cultivos, a la chacra. Los campesinos consideran a las papas de su chacra como a sus hijas y cuando recién se incorporan le dan el nombre de nueras" (Rengifo 1996, 4). ${ }^{12}$

${ }^{12}$ Como ya hemos indicado, el trabajo de Rengifo expresa de modo comprimido los contenidos que queremos desarrollar. La referencia "agrocéntrica" que destaca tiene para nosotros el valor fundamental de saber situar una referencia trascendental: el fuerte contenido material de unas culturas que no son susceptibles de comprenderse de modo "cosmológico", como hacen otros autores que, a nuestro modo de ver, cargan todavía un eurocentrismo, reproduciendo inconscientemente categorías que nunca se detienen a critizar y, consecuentemente, deducen de ellas ya no aproximaciones sino encubrimientos de lo que quieren expresar. En toda "cosmología" tiende a desaparecer el ser humano; el logos del orden toma el carácter de un orden trágico y necesario, lo cual produce una ontología de la dominación. Nos referiremos a una cosmovisión 
La personificación, más que un atributo, es el reconocimiento pleno del carácter de sujeto de todo pariente potencial. Entonces, la equivalencia no es cuantitativa sino cualitativa. Lo que aparecen no son objetos sino sujetos. Sujetizar al propio producto, en este caso, la papa, manifiesta ya una cualificación no meramente economicista del mismo hecho de la producción. No existe enajenamiento entre lo producido y el productor; por lo tanto, lo producido no es una simple mercancía sino que se la comprende hasta como una nueva vida. El carácter sagrado que tiene la producción no es entonces una ingenuidad sino el reconocimiento de que una producción no es mera producción, que en la producción ya establezco el modo de relación que me define como parte integrante de una comunidad presupuesta. En ese sentido, la comunidad aparece como una noción que integra el mundo humano con todo aquello que le rodea y forma parte de ese mundo como comunidad; integración que afirma el sujeto en la propia producción. La comunidad no es algo dado sino lo que se produce.

Común y unidad, como partes descompuestas de esta noción, nos sirve para enfatizar lo que se quiere indicar: lo común es aquello en lo que todos participamos, a lo cual tendemos y expresamos en lo que producimos, que es, en última instancia, nosotros mismos (en el producto estamos nosotros, por eso, nada mejor que el producto agrícola para mostrar esto). La unidad que se expresa tiene el carácter de reunión siempre en proceso de realización, por eso se trata de una reunión de la cual se parte, pero también a la que siempre se tiende, en un continuo desiderátum que pone en movimiento a la existencia. Por eso es una unidad que agrupa parientes.

Esta agrupación es siempre extensiva, dispuesta siempre a la integración continua de nuevos parientes: "Decir papá, tío o hermano a las personas de la generación de nuestros padres o de las nuestras, sean o no parientes consanguíneos o afines, es una manera usual de comunicarse en los Andes" (Rengifo 1996 , 4). Se dice también tíos, tías a ciertas personas sobrenaturales ${ }^{13}$ a las

y no a una "cosmología"; el hincapié en la primera radica en la visión, que es siempre la perspectiva, el punto de vista, de un alguien concreto, un alguien presente en la visión no como objeto sino como sujeto. Una labor pendiente en el discurso "descolonizador" que se maneja repetidamente es, precisamente, el desmontaje de todo el marco categorial moderno-occidental.

${ }^{13}$ No recurriremos a la denominación de "divinidades", pues esta figura no expresa adecuadamente el contenido, más familiar, de Wacas, Apus, Achachilas, etc. En adelante será wacas la denominación que adoptaremos para significar lo que no es precisamente natural. La vinculación con lo sagrado, en el mundo "andino", no genera distanciamientos; lo familiar trasciende lo estrictamente humano, de modo que el ser humano no vivencia su existir como un estar-arrojado o yecto, 
cuales se rinde cierto culto y que son siempre mencionadas en las ch'allas $^{14}$ o en diversos actos rituales. Esta manera de personificar es el modo extensivo que adquiere la comunidad en los términos de comunidad de parientes. Este parentesco no es algo fijado sino un algo que se va extendiendo como el modo que tiene de estar-siempre-siendo ${ }^{15}$ la comunidad. En el ayllu no podría haber alguien ajeno. Podrían aparecer desconocidos, pero siempre en potencia para hacerse conocer y rejuvenecer el ayllu. La renovación no proviene necesariamente desde adentro del ayllu ya conocido. Por eso, el modo-de-ser del ayllu es un ir siempre trascendiendo sus determinaciones. No se agota en lo que ya es sino se relanza siempre a lo que todavía no es.

Nadie es ajeno del ayllu, pues no hay nadie que no provenga de un ayllu; en este caso, un nadie o un don-nadie (o hasta un hijo de nadie) es algo inconcebible. El individuo no puede entenderse al margen de su ayllu, su modo de vivenciarse ${ }^{16}$ es siempre como perteneciente a su ayllu. Pero como indica Rengifo, este su ayllu no siempre es único ni tiene linderos físicos fijos:

En cierta circunstancia mi ayllu es mi comunidad o sea ayllu de ayllus. Pero cuando se está en la comunidad puedo decir que pertenezco al ayllu de mi apellido paterno, o al de mi apu de referencia, o al sector en que vivo. En otro contexto, p. e., si estoy en la capital de la provincia, y si se me pregunta de mi ayllu puedo responder aludiendo al nombre de mi distrito al que pertenece mi comunidad y con cuyos apus me siento familiarizado, y así el ayllu puede ser también mi provincia y siempre se está en ayllu. En este sentido el parentesco es bastante plástico y sus

sino como un estar-enfamiliado; en este sentido, no hay extrañeza en los modos de relacionarse, no hay seres "sobrenaturales" ajenos a lo familiar, es decir, ajenos al encariñamiento; tampoco hay sólo cosas, pues todo tiene carácter de familia.

${ }^{14}$ La ch'alla, más que un acto de devoción, es un acto cotidiano por el cual se "paga", se ofrece, al modo del alimento, a un alguien no humano. Todo es un ser vivo quiere decir: todos son personas y tienen necesidades; por ejemplo, la casa es también persona y en cierta época del año se le "paga", se le hace fiesta, se le alimenta, de modo que sus necesidades sean también atendidas. A ciertas wacas se les invoca como Tíos o Tías, a los cerros como Achachilas o abuelos; también se invoca al Condor Mamani, como un pariente necesitado en las ch'allas.

${ }^{15}$ El "bien-siempre-está" es todavía usual en el castellano rural, para indicar el modo no estático en que se está como persona, siempre siendo y estando, nunca concluido ni acabado sino siempre abierto.

${ }^{16}$ Vivenciar no quiere decir experimentar. El experimentar señala de antemano una relación sujeto-objeto; mientras que el vivenciar quiere indicar una proximidad (no una proxemia, como diría Dussel) persona-persona, cara-a-cara, de responsabilidad mutua, recíproca. 
integrantes pueden ampliarse o contraerse en consonancia con la situación que en ese momento vive una agrupación. (Rengifo 1996, 6)

Esta elasticidad es también la elasticidad del concepto: así como sus fronteras son poco rígidas, así también su elaboración conceptual no puede ser contractiva. ¿Cómo entendemos entonces el ayllu?

El ayllu, como comunidad de parientes, no expresa solamente el mundo humano. ${ }^{17}$ Se trata de una noción trascendental que quiere expresar el carácter fundamental del modo cómo el mundo-de-la-vida "andino" comprende y vive con sentido el sentido que tiene el mundo en cuanto comunidad. No se trata de una comunidad abstracta; su modo concreto indica una comunidad de parientes. En este caso, lo común no es lo nuestro (como apropiación deliberada) o lo común del todo (por referencia ontológica a un orden dado).

Lo común dice de la proximidad más inmediata; por eso la analogía con el vientre es siempre aquello que se recalca cuando se quiere indicar la pertenencia humana a la Pacha-Mama. Ésta, como Madre por antonomasia, es el lugar de la vida que conocemos, como el vientre, el lugar que da cobijo, luz y alimento y hace posible la vida de todos: "Al ser todos miembros de mi Pacha o casa de mi ayllu, todos los que habitan dentro de ella son vivenciados como mis familiares. La misma actividad de regeneración en los runas no es sólo vivida como producto de la unión de seres de la misma especie, sino también como expresión de la actividad criadora de la Pachamama" (Rengifo 4). La Pacha-Mama no es un ente pasivo, es Madre, cuya continua actividad criadora la cualifica como persona superlativa a la cual nos debemos: así como nos cría, así también la criamos. La producción que producimos en ella es un criarle, como expresión de reciprocidad en el agradecimiento.

El ayllu no es, entonces, una mera organización, sino el modo-de-vivir en comunidad con todos aquellos que nos rodean y forman parte de la vida, por eso también se dice que estamos con-formados por todos aquellos que contiene la vida del individuo: la sallqa y las wacas $^{18}$ (la Pacha-Mama y los Achachilas). Por eso es impensable, dentro de esta cosmovisión, la separación o enajenación entre hombre-naturaleza o entre ser humano-Dios; una tal separación supondría una lejanía, un extrañamiento, una independencia

${ }^{17}$ Por eso resulta reducida aquella acepción que entiende el ayllu sólo como "una forma de organización social para los pueblos indígenas" (THOA). Se trata, como se irá mostrando, de la "comunidad como estructura de la vida".

${ }^{18}$ Lo que intentarían indicar los deficientes conceptos de naturaleza y lo sobrenatural. 
imposible. La extrañeza genera soledad, pero si todos somos familia, "no hay el concepto de soledad y orfandad sino el de amparo. El andino vive acompañado de las deidades y la naturaleza a quienes ampara, cuida y protege" (Rengifo 6). Los vivencia como parientes, con los cuales establece relaciones de dependencia recíproca, desde donde comprende la pertenencia como responsabilidad mutua; por eso puede hasta dirigirse a una waca en señal de amonestación. La responsabilidad que adquiere le hace reclamar una co-responsabilidad. La realización de la comunidad es el desarrollo de esta coresponsabilidad; por eso el runa o el jaqi ${ }^{19}$ nunca concibe su acción como aislada o sólo individual. Lo que él hace lo hace mancomunadamente. Por eso la política no le es extraña sino lo más próximo a aquello que concibe como praxis; sólo que en su praxis política, hay un añadido trascendental: toda decisión no es únicamente individual o grupal sino comunitaria, donde hacen acto de presencia los otros parientes. Si el asunto es la comunidad, nadie puede estar al margen, menos los Achachilas ni la Pacha-Mama. Afirmar la comunidad es hacer comunidad.

Pero el ayllu no es nunca algo dado ya, de antemano; es más bien un algo que se prepara. Es decir, y esta es una cualidad del concepto, no es algo apriorísticamente determinado, sino algo que el ser humano ${ }^{20}$ debe, en consonancia, con la vida, saber re-producir, re-generar y re-novar, de modo que la vida sea posible de ser continuada y ampliada. En este sentido, la responsabilidad acontece en el ser humano como la pre-disposición inscrita en su propia existencia: la preparación del ayllu es su incumbencia (desde esto es que puede convocar a las otras existencias). Preparar, en este caso, es brindar todas las mediaciones para que pueda desarrollarse la crianza: ${ }^{21}$ el ayllu, decíamos, no es sólo una relación consanguínea, sino "una comunidad de personas encariñadas del que brota una vivencia afectuosa, solidaria y saludable" (Rengifo 1996, 5).

\footnotetext{
${ }^{19}$ Lo que intentaría indicar el deficiente concepto de individuo.

${ }^{20}$ El sentido propuesto viene expresado en estas palabras de Rengifo: "De allí que en los Andes, la noción de runa (hombre en quechua) o jaque (hombre en aymara) no puede ser equiparado sin más con la noción de hombre occidental. La noción de runa no implica trascendencia de lo no 'humano', una liberación de la naturaleza sino la vivencia más íntima y afectiva de las forma de vida de la naturaleza y de las wacas en el propio 'dentro' del runa' (Rengifo 1996, 8).

${ }^{21}$ Concepto que iremos construyendo progresivamente y que desarrollaremos más adelante.
} 
Cuando el amparo y el afecto se densifican, es cuando la actividad criadora se desarrolla con plenitud. El ayllu se prepara, como se prepara una casa, para efectuar la actividad criadora. Habitar entonces, como el modo de preparar el ayllu, no indica una separación del medio ambiente: culturanatura; sino un efectuar, de modo humano, la "actividad criadora de la Pachamama". ${ }^{22}$ Esta actividad es una re-creación empática que se llama comúnmente reciprocidad: "es el 'gusto de dar y de criar con cariño' y no una 'obligación' perentoria dentro del marco de un cierto derecho tradicional de devolver lo dado" (Rengifo 1996, 5). Es una reciprocidad libre, no un simple e interesado dar para que me des; el "dar con cariño" es la pura gratuidad del ofrecer-se, del estar-a-disposición-de, el fundamento existencial del servicio como modo del dar-me a los demás.

Al criar se es también criado, el ayllu mismo se cría, se lo prepara; en este sentido, vivir en familia "implica criar la armoniosidad y el ambiente engendrador que haga brotar el cariño de la familia. El ayllu en este sentido, es la chacra que posibilita la crianza del cariño y del amparo" (Rengifo 1996, 5. Cursivas mías). Este mundo tiene sentido en la medida en que la crianza le da ese sentido; ese sentido proporciona deleite en la vida de la persona al criar y dejarse criar: la vida de cada uno facilita la vida de todos: "la crianza, tanto para quien cría como para quien es criado, es la forma de facilitar la vida, es la forma de participar a plenitud en la fiesta de la vida. Al ser todos una familia en permanente crianza" (Rengifo y Grillo 52).

Eso es lo que genera la pertenencia, el ser parte de un mundo que criamos y que nos cría; en eso consistiría la vivencia de lo comunitario: el mundo como casa, como hogar, como amparo, donde no se excluye a nada ni a nadie. La mediación estructural de este mundo, como una totalidad de sentido (como ayllu) es entonces la crianza; ésta se especifica como la

${ }^{22}$ En este caso, la indicación es importante, pues no se trata de un "crear de la nada", sino de un criar lo que hay. Esta característica es fundamental, pues explicaría el por qué no fue posible que los movimientos indígenas adoptaran posiciones anarquistas en sus luchas. Dentro de la cosmovisión "andina" es prácticamente imposible postular un algo nuevo desde la nada, una libertad incondicionada e irrestricta; es más, "preservar", "reconstituir", "restaurar", son palabras fuertes que han sido siempre enarboladas en las rebeliones indígenas: "La regeneración no es un volver a generar algo de la nada, sino el 'afloramiento' de nuevas formas de vida contenidas ya en las existentes, brotamiento que se realiza con la participación solidaria de las comunidades de runas, de la sallqa y de las wacas" (Rengifo 1996, 8). Las rebeliones indígenas pueden entenderse, de ese modo, como restauradoras, es decir, como re-vueltas a un orden anterior, restaurar una "libertad muy antigua" (Thompson 2007). 
con-versación mutua y recíproca que se genera en connivencia con el sentido del mundo; para que nadie quede excluido de la fiesta de la vida, se dice que todas las formas danzan en reciprocidad, con-versando ${ }^{23}$ siempre, criándose: "Justamente es en esta fiesta jubilosa y cotidiana del mundo vivo en donde se va criando la armonía, al ir logrando la complementariedad entre todos, al comprobar que la vida de cada quien sólo es posible por la presencia y colaboración de todos los otros. A esta comunidad de cariños de humanos, naturaleza y deidades, se denomina ayllu" (Rengifo y Grillo 52. Cursivas mías).

Entonces el ayllu no es un algo dado sino un algo a lo cual se tiende en cuanto horizonte, lo que da sentido al mismo hecho de preparar las condiciones de su realización. El ayllu se vivencia en ese preparar; por eso el preparar es, en realidad, un preparar-se. Por eso, también, me considero ser humano, persona, jaqi, en cuanto soy y me comporto como un criador. El sujeto es un criador. Ese su estar sujeto $a$, es una re-ligación que se produce de modo auto-consciente en la misma crianza.

Ahora bien, el sentido mismo del preparar es el que señala una responsabilidad y, en la perspectiva que estamos indicando, una clara referencia de contenido político: si el ayllu se prepara, esto quiere decir -repitamosque no es algo dado sino que implica una responsabilidad del sujeto que, en el caso práctico, se trata de una responsabilidad política: "el ayllu, en este sentido, es la chacra que posibilita la crianza del cariño y el amparo" (Rengifo 1996, 6).

Para que haya crianza tiene que haber chacra. La chacra es el mismo preparar: el lugar donde la crianza se producirá. Pero no todo lugar pide chacra, es decir, no hay un disponer exclusivo del ser humano; aquí también se precisa de la con-versación, pues no todo lugar es lugar adecuado: todo tiene su tiempo y lugar y, en este caso, es el lugar el que, en la con-versación, pide ser chacra: "Es un ambiente de continua incorporación de nuevos miembros y la renovación de otros que pasan a descanso, pues la vida en ella es dinámica y a ciclos de mucha intensidad, le siguen ciclos de contracción. Las pruebas siguen estos ritmos y pulsaciones, lo que equivale a indicar, como dicen los campesinos, que: todo tiene su tiempo" (Rengifo 1991, 215).

\footnotetext{
${ }^{23}$ También se dice que con-versar es danzar, pues en la danza uno lleva y se deja llevar; para llevar hay que saber a dónde llevar, y dejarse llevar implica una docilidad y obediencia a alguien que sabe llevar.
} 
La chacra es el lugar donde se re-crea la vida y se la llena con nuevos parientes, más formas de vida que acompañan a la regeneración de ésta. En este sentido, la chacra excede el ámbito estrictamente agrícola y constituye todo "ámbito de conversación que renueva la multiplicidad de formas de vida" (Rengifo 1996, 20). Por eso encontramos en todos estos conceptos la potencialidad de una concepción de la política (no en su estrechez moderna sino en su viva complejidad) que los movimientos indígenas han venido practicando pero que, como se carecía de categorías pertinentes para entenderla, quedaban, a lo sumo, como mero anecdotario de nociones "extrañas".

Entonces, el ayllu es un modo (nuestro modo, humano, como sincronía con el modo de todo) de acomodarnos entre nosotros, ${ }^{24}$ comunitariamente, en continua con-versación entre nosotros y con los otros modos de vida con quienes compartimos nuestra localidad, nuestra pacha, para seguir viviendo y engendrando más vida. De ahí el sentimiento de incompletitud de cada quien porque bien sabemos que nuestra vida sólo es posible dentro de ese hervidero de vida que es el mundo comunitario andino (Rengifo y Grillo 54$55)$.

El sentimiento de no estar nunca completo no indica una dependencia negativa sino el salir de sí como movimiento existencial de una subjetividad que se acrecienta, a medida que se trasciende: cuando ese salir de sí vuelve $a$ sí, vuelve enriquecido y con el impulso siempre renovado de salir más allá. Lo afirmado entonces, más que el ego, es ese movimiento relacional que produce comunidad: la reciprocidad. Criar y ser criado es esa reciprocidad que mantiene, conserva y ampara, este tejido que se conforma: el ayllu.

Pero la crianza no es un modo autónomo de ser del ayllu, sino el modo como se realizan los sujetos haciendo ayllu. Se podría decir que el proceso de individuación aparece al criar y ser criado. Por eso la comunidad de parientes es, en consecuencia, una comunidad de criadores. Criar es con-versar. La crianza es recíproca porque la con-versación es recíproca. La individuación es un proceso continuo de crianza, donde el aprendizaje es extensivo y sugiere un incremento de la subjetividad por la capacidad de apertura que significa el

${ }^{24}$ La descomposición de la palabra nos ayuda a indicar la doble presencia del nosotros: el nos y los otros, no sólo de lo humano y de lo que no lo es, sino también de aquella extrañeza que surge cuando un determinado mundo se ontologiza, es decir, se cierra. El sentido expansivo-trascendental del ayllu sería el modo de continua apertura que impediría su ontologización. 
criar y ser criado, en todo ámbito de ayllu, que excede siempre lo estrictamente humano.

De este modo, se puede advertir, en los términos indicados: preparar el ayllu es una responsabilidad política, no sólo porque la responsabilidad es común, o porque el hacerse cargo de la comunidad, que es una manera de criar, es el modo de individuación, sino porque ese tipo de dis-posición, no se deduce de las prerrogativas de un oficio; responde a un algo anterior de toda consideración vocacional, responde al modo comunitario del existir. Criar es también servir. $\mathrm{Y}$ este modo, el servicio comunitario, es lo que constituye la cualidad política del hacerse cargo de la comunidad. Por eso el servir resulta lo más sublime, porque sirviendo crío la continuidad de la vida, hago comunidad, es decir, restauro continuamente el mundo en cuanto comunidad. Hacer comunidad o hacer ayllu sería algo como hacer nido para que la vida toda pueda regenerarse. En eso consistiría ser humano, o sea, jaqi o runa. Por eso, la comprensión que del sujeto se desprende de esta cosmovisión no puede nunca reducirse a la intelección pura. El sujeto es práctico, en este sentido, político.

Pero antes de definir este modo cualitativo que adquiere lo político en esta cosmovisión, queremos resaltar su aspecto material y la ligazón íntima entre el sujeto y aquello a lo cual está sujeto de modo inmediato: la PachaMama. Esto nos servirá para subrayar el hecho de que toda política no puede no incluir, de modo explícito, la materialidad de la vida, y que ésta es, en última instancia, la razón por la cual, la política es posible y necesaria para la vida, tanto humana como no-humana.

Por eso, la libertad humana no puede fundarse sino en la responsabilidad, que es el modo de indicar una pertenencia trascendental que sujeta al ser humano a la Tierra. La política tiene, de este modo, una normatividad implícita, que se expresa como responsabilidad en el servicio. Criar y ser criado: servir es ser merecedor de la vida. La política sólo puede ser política para la vida.

Se podría objetar que nuestra aproximación pareciera idílica. Pero cabe indicar lo siguiente: estamos describiendo, de modo hermenéutico, el modelo trascendental que presupone el concepto; es decir, nos movemos todavía de manera propedéutica. Si este momento aparece sin contradicciones es porque nos encontramos todavía en el nivel abstracto, donde los conceptos aparecen todavía sin determinaciones; no hay todavía movimiento real, en consecuencia, el despliegue, todavía simple, desata ya su propia complejidad, a medida que el horizonte se nos adviene. Es en el proceso de sus posibles 
determinaciones, para usar lenguaje hegeliano, que aparecen, inevitablemente, las contradicciones. Pero, insistimos, se trata del modelo ideal que proyecta el sujeto en su exposición. La lectura hermenéutica extrae de esa exposición lo que de genuino proyecta y que, en la irrupción política que hace, se expone de mejor modo. La comunidad no es un mundo sin contradicciones, tampoco la disolución de éstas; precisamente porque la comunidad no es un algo dado, sino un producir, supone que ésta nunca está asegurada sino abierta (lo que implica también siempre un riesgo) a la restauración, regeneración y renovación. Ésta es la tarea que el sujeto asume de modo autoconsciente, porque puede también suceder la desconstitución de la comunidad.

Otra objeción sería que esta investigación carece de sostén empírico que pueda afirmar sus hipótesis. Pero esa misma objeción no es sino resultado de la deficiencia epistemológica y metodológica que arrastra la ciencia social estándar en el modo cómo se relaciona con la realidad: "La teoría del fetichismo de Marx sostiene que para una ciencia en la cual las relaciones de dominación aparecen simplemente como lo que son, la misma realidad llega a ser invisible. No tiene más que una empiria. De esta manera se le escapa precisamente todo lo que es condición de la vida [...]. Sin embargo, la teoría la excluye. La excluye al decir solamente lo que es. Eso le permite ser útil en las prácticas de la vida normal para entender la manera de actuar de aquellos, que se mueven en una sociedad mercantil adaptándose simplemente a ella" (Hinkelammert 11. Cursivas mías).

Insistimos, la re-construcción que estamos exponiendo es conceptual y quiere describir el horizonte de comprensión comunitario que presupone el mundo-de-la-vida "andino"; entonces, una contrastación supuestamente "empírica" con el mundo rural carecería de valor, pues lo contrastado es, en la mayoría de los casos, con un mundo si no descompuesto, en proceso constante de descomposición (esto quiere decir: de modernización), por la penetración sistemática de patrones de vida adversos y atentatorios al modo de existencia que estamos tratando de describir.

Si se halla en descomposición, ¿cómo es que pretendemos exponer lo suyo-de-si del sujeto? Esta descomposición la sufre el sujeto y esto es lo que expone como la contradicción inherente que manifiesta su condición escindida; privado de su mundo, muestra, sobre todo en su inserción en la lucha política, la necesidad de re-equilibrar una pertenencia que le devuelva el sentido que sufre perder (por eso, cuánta más crítica es su deprivación, más genuina es su lucha). Por eso no se trata de hacer una cronología de sus 
luchas o una acumulación de sus apareceres sino de acceder al contenido que da sentido a todo aquello.

La "objetividad" que se nos reclamaría, no sería sino la claudicación: la consagración de lo que es; el hecho constituido deducido de las definiciones anticipadas que ya se tiene. En nuestro caso, la realidad objetiva no es algo dado, clausurado en sus potencialidades, sino la realidad que se corresponde con la transformación de un proyecto en realidad. Por eso repetimos: la articulación compleja entre el horizonte de comprensión presupuesto (esa densidad temporal como lógica de acumulación de la memoria histórica hecha política de resistencia) y el potenciamiento de la realidad (como proceso histórico de transformación de un proyecto en realidad), no puede ser reducido a sus mediciones empíricas. En este ámbito prima el fenómeno pero, en términos epistemológicos, los fenómenos no pueden dar razón de sí mismos. En ese sentido, lo empírico es dato pero no es fundamento. Sin fundamento, todo es dispersión, las partes son puro fragmentos sin totalidad. Por eso la recurrencia a un horizonte trascendental que articule todo lo disperso que uno encuentra en las manifestaciones empíricas. Ese horizonte es lo que deseamos explicitar, porque es el horizonte que fundamenta las prácticas que expresan al sujeto que expresa ese horizonte.

\section{La responsabilidad política por la Tierra}

La chacra, como todo ámbito de con-versación, excediendo de esta manera su exclusiva referencia agrícola, muestra la íntima ligazón, denotada semánticamente, del ser humano con la Tierra, con la Pacha-Mama.

La palabra chacra se traduce frecuentemente por naturaleza, ${ }^{25}$ pero nuestro énfasis sugerirá, más bien, su traducción por algo más telúrico: la

${ }^{25}$ El contenido del concepto naturaleza tiene una historia específica y en ella aparece una comprensión particular, no universal, de lo que se entiende por ella: "El humanismo y el Renacimiento comenzaron a imponer un nuevo esquema. La naturaleza cobró paulatinamente el esquema de una máquina: natura naturata, que funciona gracias a ciertas leyes fijas impuestas por la misma naturaleza (natura naturans). Todo esto no se hizo en un día sino que necesitó siglos" (Dussel 1978, 195). El concepto naturaleza se constituyó con toda una carga ontificante quizás necesaria para humanizar un ambiente hostil (pues su divinización era producto del temor que infundía a los pueblos del norte de Europa). La cristiandad tardó siglos en humanizar la "selva negra", es decir, en naturalizarla, pero eso también supuso su secularización; es decir, su 
Tierra. Esa íntima ligazón desaparece si el concepto se vacía de materialidad, es decir, de corporalidad, de terrenalidad; en consecuencia, la personificación de Ella resultaría en - como en la tradición latina - una serie de atributos abstractos que dicen muy poco de su existencia real y concreta. ${ }^{26}$ En este sentido, la noción de Pacha precisa re-semantizarse e insistir en esa fuerza originante de las existencias, ${ }^{27}$ voluntad dual que muestra el prefijo $p a^{28}$ y que manifiesta, en cuanto voluntad, ese impulso inicial que tienen las existencias para salir de sí.

Ya señalábamos que la "esencia" de la voluntad es la vida, que la vida misma es nada sin voluntad, que su fuerza creadora es fuerza de voluntad que, como tal, es todavía la fuente indeterminada de toda determinación que pueda perseguir la vida. Ésa es la cualidad que queremos destacar, porque el

desdivinización tuvo, como consecuencia, su instrumentalización: objeto a disposición.

${ }^{26}$ Por ejemplo la definición que hace Boecio sobre persona: "sustancia individual de naturaleza racional". En la descripción que estamos realizando ésa es una pura abstracción que más parece definir a un ente vacío de toda existencia, porque únicamente hay persona en el reconocimiento mutuo, intersubjetivo. Se podría argumentar que personificar es el reconocimiento de la dignidad absoluta que posee alguien como persona, es decir, que sólo hay persona en una relación recíproca. Una sustancia individual jamás podría ser persona, pues no tiene con quién establecer una relación personal (Dussel 2004).

${ }^{27}$ Que haya existencias no quiere decir que haya vidas, pues lo que se despliega en toda existencia es la vida misma, que se contiene, como impulso, en la partícula pa. Por ejemplo, si el Alaxpacha es los cielos, el arriba, y el Mankapacha es el nivel de abajo, de lo oculto, lo que se quiere indicar no son simplemente espacios sino tiempos (el futuro y el pasado), por eso pacha ajayu se traduce como la "fuerza del tiempo". El impulso inicial de la vida, siempre como voluntad, es el inicio de todos los tiempos. Fernando Huanacuni, a esta trilogía quechua, aumenta una cuarta dimensión, según la lógica específicamente aymara: el Kaukipacha o el tiempo del acaso, lo posible, podríamos decir: la dimensión utópica (Huanacuni 2010).

${ }^{28}$ Que indica no una dualidad, como generalmente se lo concibe, pues esto casi siempre deriva en una lógica de la oposición (dualismo metafísico). Indica la paridad del impulso inicial, lo cual es coherente con las cosmovisiones más antiguas: "En Hermópolis será Thot el creador-ordenador del cosmos. Los textos cuasi-filosóficos de Menfis efectúan una nueva racionalización: Ptah es ahora el creador universal, pero la dicha creación se opera desde su corazón (Horus) y por medio de la Lengua, la Palabra, el logos, el nous: Thot, el que crea todo desde su sabiduría, es entonces anterior a la creación del universo" (Dussel 1998, 25). La palabra sola, Thot, no crea, precisa del alimento del corazón, Horus, la voluntad; esto es lo que indica una palabra llena de vida, que produce vida. Esa también ha de ser la palabra en la cosmovisión semita, dabar, y no precisamente el logos griego (este logos es imposible de hacerse carne). 
prefijo pa de Pacha, es luego complementado por el cha, que quiere decir fuerza. No hay una sola fuerza sino dos, pero no dos separadas sino dos que son par en cuanto son paridad. En el concepto de Pacha está ya expresado, entonces, el sentido de la comunidad.

Estas determinaciones del concepto nos van abriendo camino para ir reconstruyendo un mundo-de-sentido: nuestro mundo-de-la-vida. Ahora bien, la conjunción Pacha-Mama es más que una producción semántica; indica más bien, como todos los demás conceptos, una existencia que, en la misma nominación, se va revelando no como un algo sino como un alguien, como persona. Nombrar es dar vida. Por eso se dice que los cerros escuchan cuando se les llama por su verdadero nombre. ${ }^{29}$ Como en otras culturas antiguas, las palabras no actúan como meros entes de comercio sino como verdaderos tejidos de la comunidad de la vida, que los seres humanos intiman y tratan como verdadera extensión de la persona.

Por eso los conceptos siempre tienden a la personificación. PachaMama es Madre, no solamente porque es lugar y origen de lo que conocemos como vida, sino que es vida por excelencia, pero no es vida abstracta sino que, como Persona, es subjetividad dadora de vida: Madre en un sentido eminente, no un ente a disposición sino un Sujeto con dignidad absoluta. Pareciera una redundancia, porque, en el sentido expuesto, Pacha indica el impulso del tiempo como despliegue de la vida; pero la conjunción quiere indicar el modo eminente de la vida: Pacha-Mama indica ya no únicamente el impulso inicial sino el movimiento de la vida, la Madre no es dadora de vida sólo porque alumbra sino porque $d a$ vida, antes del alumbramiento y después

\footnotetext{
${ }^{29}$ A la observación de que "El hombre occidental moderno ha perdido la capacidad de dejarse criar. Pregunta a la naturaleza, no conversa con ella" (Rengifo 1995, 37) hay que agregar: ese preguntar es un literal suplicio que sufre una entidad transformada en objeto; la cosificación tiene también sus consecuencias en el plano del conocimiento. Un conocimiento que despliega una relación de poder, sujeto-objeto, despliega también relaciones de dominación; el conocimiento que se logra no es nunca dialogado, es decir, no hay nunca novedad en ese conocimiento, es simple repetición y confirmación del conocimiento del sujeto intelectivo. Este es el sujeto abstracto propio de la ontología moderna. El propósito de esta ontología es el dominio del sujeto sobre el objeto. Como lo expresara Francis Bacon, uno de los formuladores del método científico moderno: "tratar (refiriéndose a la naturaleza, la primera entidad objetualizada por la ciencia moderna) como el inquisidor trata a su víctima, torturándola hasta que entregue todos sus secretos" (citado en Leonardo Boff, "Quando começou nosso erro?").
} 
de éste: cuida, alimenta, protege, es vida que llega hasta al sacrificio por la nueva vida que se ha propuesto criar. La vida humana está, como en el vientre, en el hogar que brinda la Pacha-Mama; por eso se refiere a ella como Madre por antonomasia: nuestro lugar, como origen y como existencia, el hogar que nos protege, nos alimenta y nos llama, nos ata y nos abraza, hasta la muerte.

La familiaridad de este entorno es algo que constantemente dialoga. En ella estamos en comunidad, porque estamos en permanente diálogo. Lo común, entonces, dice a lo que está en constante diálogo. Por eso en el campo es fundamental el escuchar; se escucha el viento, los pájaros, el agua, los cielos, etc., todos dicen algo y en ese decir es que el ser humano produce el conocimiento necesario para habitar, con sentido, el mundo familiar que vive. Por eso se trata de una comunidad de parientes; el ayllu no solamente de humanos sino de todos aquellos que comparten, habitan y visitan también el lugar actual de la vida. La Pacha-Mama es ese lugar. Por eso la lucha por la Tierra es tan fundamental para los pueblos indígenas.

Si hay actualidad en este tema, es porque la defensa por la Tierra es propuesta por quienes, precisamente, saben escuchar los gritos cautivos de Ella. El sujeto comunitario habla por Ella, porque la privación de la Tierra es la enajenación absoluta; la carencia y privación de la Tierra es el locus desde el cual tiene sentido hablar por Ella.

La no tenencia tiene aquí otro modo de entender el "tener". No se trata de la propiedad de la Tierra sino del sentido que consideramos cuando nos referimos a la Tierra como nuestra. Al conjunto de derivaciones que se desprende de la lógica de la propiedad se opone, de este modo, la lógica de la pertenencia. Consideramos algo nuestro cuando el grado de relación se establece en términos de pertenencia. O sea, ¿qué se quiere decir cuando se dice mi pueblo o mi mujer? La pertenencia se entiende como aquella gratuidad pasiva (la paciencia de la caricia que espera la respuesta siempre libre) del merecedor; como diciendo: "yo pertenezco a mi pueblo porque nací en él", "yo pertenezco a esa mujer y no a otra, porque ella me tomó un día para siempre", etc.

La pertenencia es una relación de responsabilidad agradecida; por ejemplo, soy (es decir, tomo conciencia de lo que soy) desde que alguien me hace descubrir (la novedad en la que me descubro a mí mismo) mi propia singularidad. La dialéctica del descubrimiento de lo que soy, precisa de la 
otredad; ${ }^{30}$ por eso, lo que me define no es nunca mi propio yo sino la relación personal que establezco y que me descubre como lo que soy (por eso se dice: lo que nos define no es lo que nos confirma sino lo que nos desafía, y lo que nos desafía casi nunca proviene de uno mismo). Se trata de un movimiento trascendental que atravieso en cuanto relación, ${ }^{31}$ con una presencia que me acontece, precisamente, como acontecimiento. Del mismo modo, soy esto que soy porque nací en un lugar, donde fui esperado y recibido, porque en ese lugar se me fue regalada la vida; le dio a mis ojos el regalo de verle, a mis manos el suelo donde se cultivan cultivándola, el aire y el viento para que mi boca pueda hablarle y cantarle, etc.

Pero la lógica de la propiedad diluye esta pertenencia y esta responsabilidad y estima más bien la condición de la posesión, de modo que la pertenencia se transforma en dominación. Yo no pertenezco a ella, ella me pertenece; la relación ya no es de merecimiento sino de imposición de uno sobre otro. Algo es propiedad cuando es reducido a cosa: alguna cosa como cualquier otra. La cosa no puede reclamar pertenencia, su ubicuidad sólo se determina cuando sirve a los fines que se propone el posesor, es decir, cuando se subsume como medio de un fin que le es impuesto.

En tal situación, la libertad se devalúa en una relación de oposición, donde la lógica de la propiedad determina la libertad como incremento en el tener. De modo que se devalúa toda otredad en mediación: todo aparecer en el horizonte de la propiedad queda determinado como objeto a disposición; esto hace posible una relación de dominio eficaz con los utensilios (la tecnología moderna), pero hace imposible construir relaciones humanas sobre ello: toda relación humana acaba siendo inhumana cuando los seres humanos se degradan a mera condición de objetos a disposición.

Degradar todo a condición de objeto es necesario en una lógica de la propiedad. Porque dentro de esa lógica el sujeto se sustantiviza y hace del resto una indiferencia predicativa; pues el sujeto es el único actor que, en el uso del verbo, garantiza para sí toda acción en y sobre el resto (que está a disposición de sus apetitos). La violencia se garantiza por la gramática y, de ese modo, se reproduce en la naturalidad del lenguaje cotidiano. Por eso se hace necesaria la re-semantización de lo mío y lo tuyo, es decir, pasar

\footnotetext{
${ }^{30}$ Para una discusión de la otredad consultar Emmanuel Levinas, De otro modo que ser o más allá de la esencia.

${ }^{31}$ Ver Emmanuel Levinas, Totalidad e infinito, sobre todo capítulos 3 y 4.
} 
lógicamente de la propiedad a la pertenencia (en términos políticos, del individualismo social a lo comunitario).

Esto es necesario cuando se trata de desmontar una estructura que se reproduce inconscientemente en el momento racional por excelencia: la palabra. En términos de la propiedad, las fronteras y las delimitaciones garantizan la separación y la desigualdad; en la pertenencia nos remitimos a lo que nos une (el pacto presupone esta lógica, pues se pacta desde una situación originaria que nos remite siempre a una pertenencia común).

Dentro de la lógica de la pertenencia, la Tierra no es entonces un algo sino un Alguien, cuyo artículo la determina también sexualmente, es decir, es Ella, la Tierra. Por eso se le dice Madre: Pacha-Mama. La relación que se establece es filial, es de Madre a hijos. Los hijos hablan y sufren por la Madre cuando ésta les es enajenada. Los despojados de Tierra son como huérfanos que lloran por la Madre cautiva.

La Madre llora en las lágrimas de sus hijos. Su reclamo por Ella no se expresa en términos de propiedad sino de pertenencia. Nosotros pertenecemos a la Tierra como los hijos pertenecen a la Madre. Los pueblos indígenas hablan por la Tierra porque todavía se comunican con Ella; en su cautividad reconocen la cautividad de ellos. Por eso se despierta de modo interpelador: ya no se trata sólo de la sobrevivencia de los hijos sino de la vida misma de la Madre. La privatización de la tierra socava la existencia misma de la Madre.

Los que la reclaman son los merecedores de llamarse hijos, porque Ella misma no puede liberarse de una condición que la condena a privarse de su fuerza, es decir de su vida, concebida como riqueza para el disfrute de unos cuantos y la miseria de muchos. Esto es lo que produce su miseria, que se traduce en la pérdida de su capacidad reproductiva; lo cual señala un irracional (como literal) aprovechamiento de sus generosos favores.

Como Madre, la Tierra, no puede negarse a dar a los hijos lo que le piden, hasta el extremo de privarse del propio alimento y condenarse a una situación anémica (la crisis ecológica es la constatación de una desenfrenada e irracional producción que destruye, sistemáticamente, su capacidad reproductiva). Situación que se produce en una economía que se sostiene sobre el valor inobjetable de la propiedad privada, donde lo que se priva es lo común. Privar a los demás de lo que es común, significa destruir la comunidad, hacer imposible su regeneración.

El capitalismo es una economía que piensa en cómo incrementar infinitamente la riqueza, pero descuida lo fundamental: cómo preservar las fuentes de toda riqueza posible: el ser humano y la Tierra. Estas fuentes no son como el afán de riqueza: infinito. Son finitas, es decir, son fuentes que se 
pueden secar. Sin seres humanos no hay reproducción del capital. Sin Tierra no hay reproducción de la vida. Pero si todo tiene condición de objeto entonces nada tiene dignidad, todo vale por lo que se le puede sacar. La lógica de la acumulación se justifica en la ilusión de la explotación infinita, sin advertir las consecuencias de tal lógica: la vida misma es finita y no se la puede concebir de modos infinitos. Concebir la Tierra de modo infinito es haber abstraído su condición de sujeto y haberla devaluado a un puro espacio de disponibilidad total.

Hablar por la Tierra es hablar, en definitiva, por la vida. Hablar por Ella significa concebir una economía del merecimiento, es decir, una economía para la vida. ${ }^{32}$ Los pueblos indígenas, en cuanto sujeto comunitario, son ahora los portavoces de la lucha política por la Madre. La liberación ahora presupone la liberación de la Madre; no será posible una verdadera liberación humana si no hay, de modo previo, una liberación de Ella. Ese es el testimonio actual del sujeto comunitario, porque el horizonte de sentido que le sostiene presupone a la Tierra no como objeto sino como Sujeto, cuya jerarquía obliga a la responsabilidad y la obediencia. ${ }^{33}$

Por eso, este hablar por la Tierra aparece en una situación crítica. Es un grito que clama y reclama, que interpela y convoca a la lucha (porque es la vida lo que está en juego); lo cual deriva en movilizaciones, levantamientos, violencia; porque se trata del dolor de la Madre que desata la indignación de los hijos, pues son también hijos quienes lastiman de muerte a la Madre por aquellos apetitos de una codicia sin límites. Eso produce injusticia pero, lo más grave, produce la imposibilidad de la vida misma.

32 Se trata de una economía que no se fundamenta en optimizar la tasa de ganancias sino en asegurar la vida de la comunidad toda y, en especial, la vida de la Madre. Una aproximación fundamental, en este camino, da la obra de Hinkelammert, particularmente en Hacia una economía para la vida (2005).

${ }^{33}$ Lo cual se determina política y económicamente en lógicas más racionales y universales que la racionalidad moderno-occidental. Las contradicciones que arrastra esta racionalidad no es sólo asunto de una séptima parte de la humanidad, sino que arrastran a todo el conjunto de la humanidad cuando lo que se encuentra en peligro no es una civilización, ni siquiera una cultura, sino la vida misma del planeta. Reestructurar y recomponer otras formas de vida, en esta coyuntura mundial, demanda no solamente su posibilidad sino su necesidad; sobre todo cuando hablamos de restablecer una dignidad humana que supone el merecimiento de un ser para la vida. 
La Tierra también toma partido, porque le afecta la condición ética de quienes la intervienen. La crisis climática no es un simple grito sino un grito con sentido. Dice algo y lo que dice, lo dice para todos. La siguiente afirmación es elocuente, proviene de una cultura milenaria como la nuestra y expresa esto que decimos, de modo evidente: “¿Qué has hecho? La voz de las sangres de tu hermano está clamándome desde la tierra" (Libro de Bereshi o también Génesis, 4:10. Cursivas nuestras). ${ }^{34}$ Es la Tierra la que clama la pérdida del hermano, porque es la Tierra la que recibe la sangre derramada, como testigo impotente de lo que se comete contra el hermano.

La lógica de la pertenencia establece la re-ligación obediente y responsable con lo que nos sobrepasa y trasciende. De modo que la trascendencia es posible para una finitud (la humana) que contiene lo que le sobrepasa como reconocimiento propio de su necesidad de absoluto. ${ }^{35}$ Cuando se dice: "La tierra no puede venderse a perpetuidad, pues Mía es la tierra, ustedes son sólo forasteros y residentes respecto de Mí" (Libro de Vayikra 25 o también Levítico), se produce una enunciación similar a la respuesta del cacique Seattle: “¿Cómo puedes comprar o vender el cielo y el

${ }^{34}$ Se dice "sangres", en plural, porque la Tierra clama no sólo por Abel, el hermano, sino por toda su descendencia; es decir, un acto injusto no perturba sólo el presente sino todos los futuros posibles (y el pasado, pues la maldición que recae sobre el homicida maldice también su memoria: al convertirse en asesino convierte en asesinos a todos sus antepasados). Como otras tradiciones anteriores a la modernidad occidental, la tradición hebreo-semita tampoco responde a una relación sujeto-objeto. Se podría decir que la modernidad es la única cultura que se sostiene sobre esta relación, por eso su impacto sobre el resto del mundo es contundente: hace posible una producción y concentración de la riqueza nunca antes vivida, ni siquiera imaginada. El desarrollo de la tecnología moderna responde a una desmesura: la satisfacción de todos los deseos, habidos e inventados. Las necesidades se dejan de lado y las preferencias aparecen como criterio único de satisfacción; pero las necesidades se cumplen en su satisfacción, las preferencias no, se transforman en deseo, en afán desmedido de perseguir lo inalcanzable.

${ }^{35}$ La modernidad amputa toda posibilidad de trascendencia, pues se pone a sí misma como lo último, único y absoluto, de modo que todo movimiento es un perpetuo, eterno y trágico devenir de lo mismo sobre sí mismo. Un mover que no se mueve sino que da vueltas sobre sí (como el movimiento de una bicicleta estática). Pero si no hay trascendencia, entonces, no hay salir de sí hacia lo más allá, no hay movilidad y eso produce una cultura de lo efímero y lo superfluo, de la banalidad, de la cosificación de las relaciones humanas. La mercantilización de todo es la consecuencia del temor, en última instancia, del tiempo. El afán desmedido por las cosas es un querer negar el tiempo, que nos sorprende llenos de cosas pero vacíos de vida. 
calor de la Tierra? Tal idea nos es extraña. Si no somos dueños de la pureza del aire o del resplandor del agua, ¿̇cómo puedes entonces comprarlos?"136

Aquello que no tiene carácter de propiedad tampoco tiene carácter de compra o de venta. Lo que tiene carácter de pertenencia tiene carácter de merecimiento, de este modo se entiende la exhortación como mandamiento: "Si tu hermano empobrece y pierde su habilidad para la auto-manutención, deberás sostenerlo, sea prosélito o residente, para que pueda vivir junto a ti" (Libro de Vayikra 25 o también Levítico. Cursivas nuestras). La Tierra es una bendición para el ser humano, de manera que esa bendición debe ser reproducida para con su prójimo. El prójimo es aquel que debe ser sostenido, el hermano que empobrece y no puede reproducir su vida. El despojo es testimonio viviente de que la Tierra sufre impotente, una injusticia monu- mental que no re-liga sino des-liga al ser humano de su Madre. Por eso se dice: no te afanes en darle buena tierra a tus hijos sino en darle buenos hijos a la Madre.

La lucha por la Tierra es lucha, en última instancia, por la vida. Esa defensa se determina también como lucha por el territorio. Porque no se nace ni se vive en toda la Tierra sino en un lugar de Ella: en un territorio, lo que llamamos mi pueblo, mi ayllu. ${ }^{37}$ El lugar como la casa, al que retornamos siempre, en realidad y en sueños, como lugar que nos es dado y al cual nos debemos. En la lógica de la pertenencia la libertad es responsabilidad, por todo y por todos. El ser humano es el eslabón último que ha creado la vida, es el que pone a su cargo una obligación moral: responder por y ante la comunidad. ${ }^{38}$ El discurso ya no es mera retórica, sino el testimonio del haber escu-

${ }^{36}$ Se trata del famoso discurso del jefe Seattle, cacique de los Duwamish, pronunciado ante Isaac Stevens, gobernador del estado de Washington en 1856. Publicado el 29 de octubre de 1877 en el Seattle Star.

${ }^{37}$ En este sentido, pueblo no indicaría, en cuanto ayllu, sólo la comunidad humana sino la comunidad de, en palabras de Rengifo, runas, sallqa y wacas. Por eso, tampoco la política puede circunscribirse sólo a lo estrictamente humano, y eso adquiere notoriedad hoy en día, cuando el tema ecológico cobra inquietud pública y política. La responsabilidad política del ayllu es trascendental; excede lo meramente humano en una cosmovisión donde el orden humano participa de los otros órdenes y viceversa. Esto, inevitablemente nos lleva a una ampliación del concepto que tenemos de pueblo.

${ }^{38}$ Cuando se dice ser humano se dice ser capaz de autodeterminación, es decir, de autonomía, capacidad de juicio o vida moral, esto es, un ser capaz de responder de y por sus actos ante todo y ante todos, eminentemente auto-reflexivo, autoconsciente; en definitiva, un ser libre. No se trata de algo que se le impone de afuera sino algo que asume el sujeto, en su propio reconocimiento. Por eso se puede hacer autónomo, es decir, con obligación moral, porque autonomía quiere 
chado la insistencia de restaurar lo que nos es común: nuestra comunidad-devida. Los signos de la vida lo reclaman, la Madre lo reclama, hasta los Achachilas reclaman la restauración de la vida como comunidad-de-vida. Responder por la vida toda, en este caso, es el modo trascendental que resignifica la política en cuanto responsabilidad comunitaria. No se trata de la política participativa sino del sentido mismo de la participación. Participamos porque asumimos que hay algo común que nos reúne (esto que nos reúne nos excede) y que, en el hecho de la participación plena, nos confirma como lo que, en última instancia, somos: comunidad de criadores. Ese es el sentido que nos hace responsables: el hacernos cargo de restablecer lo que nos define y nos es común.

\section{Bibliografía citada}

BAUTISTA S, Rafael. Pensar Bolivia bajo el cielo de octubre. Manuscrito inédito.

---. 2006. "La ambigüedad del mito del Pachakuti". Ponencia presentada en el VI Encuentro Nacional de Filosofía y Humanidades. Cochabamba.

---. 2006. Octubre: el Lado oscuro de la luna. La Paz: Tercera Piel.

BOFF, Leonardo. 2008. “Quando começou nosso erro?” ALAI (América Latina en

decir autodeterminación: el desarrollo que la conciencia produce como autoconciencia, como constitución de su existencia en existencia responsable. La perversión en que la autonomía ha devenido da cuenta de un individuo que pareciera no tener ninguna obligación moral y menos pública. Se trataría de la relativización de la moral, la separación y la división como forma de vida. Una lectura de los "estatutos autonómicos" (disfraz que ahora presenta el colonialismo interno) nos muestra que no son resultado de un proceso de autoconciencia, ni la producción de conocimiento propio; sólo representan una asunción ciega del patrón hegemónico de dominación. Por eso pretenden la conservación de una delimitación colonial como la departamental, donde se administra políticamente la desigualdad económica. Desconociendo a la víctima su territorio, se le niega su autodeterminación, su dignidad de sujeto de derechos humanos y políticos. Por eso los "autonomistas" quieren asegurar para sí la potestad sobre la Tierra. Así, el subordinado piensa que toda libertad radica en el atropello de la libertad ajena y acaba exponiendo su condición de sometido: no saber otra forma de ser algo que atropellando a otro para agradar a alguien que ni siquiera es él. Dominar para ser como el amo y hallar así su reconocimiento es ridículo, porque busca lo que no sabe ni siquiera encontrar en sí mismo. La verdadera autonomía proviene de las verdaderas víctimas, las naciones indígenas y originarias. Ellas son las que le enseñan al siervo que no hay vida posible si no hay también autodeterminación, es decir, ser sujetos de nuestro propio desarrollo. 
Movimiento). [http://alainet.org/active/26806\&lang=es] página descargada el 15 de febrero, 2013.

Discurso de Seattle, cacique de los Duwamish. 1877 [1856]. Leonardo Boff. 2011. Ecología: grito de la tierra, grito de los pobres. Madrid: Editorial Trotta. 274-277.

DUSSEL, Enrique. 2008. Marx y la modernidad. La Paz: Rincón Ediciones.

---. 2004. Ética comunitaria. Obra filosófica de Enrique Dussel (1963-2003). CD- ROM [http://www.afyl.org/cd-info.html] página descargada el 15 de diciembre 2012.

---. 1998. Ética de la liberación en la edad de la globalización y la exclusión. Madrid: Editorial Trotta.

---. 1990. El último Marx y la liberación latinoamericana. México: Siglo XXI.

---. 1988. Hacia un Marx desconocido. México: Siglo XXI.

---. 1978. Desintegración de la cristiandad colonial y liberación. Salamanca: Sígueme.

---. 1975. El humanismo helénico. Buenos Aires: Eudeba.

---. 1969. El humanismo semita. Buenos Aires: Eudeba.

HABERMAS, Jürgen. 1987. Teoría de la acción comunicativa. Vol. I y II. Madrid: Taurus.

HEGEL, G. W. F. 1968 [1948]. Ciencia de la lógica. Augusta y Rodolfo Mondolfo, trads. Buenos Aires: Ediciones Solar.

HEIDEGGER Martin. 2000. Ontología. Hermenéutica de la facticidad. Madrid: Alianza.

HINKELAMMERT, Franz. 2008. "Sobre la reconstitución del pensamiento crítico". Polis. Revista de la Universidad Bolivariana. Vol. 7/21 367-395.

[http://www.scielo.cl/pdf/polis/v7n21/art17.pdf] página descargada el 15 de diciembre 2012.

---. y Henry M. Mora. 2005. Hacia una economía para la vida. San José, Costa Rica: Editorial DEI.

HUANACUNI MAMANI, Fernando. 2010. Vivir bien/Buen vivir. Filosofía, políticas, estrategias y experiencias regionales. La Paz: Convenio Andrés Bello, Instituto Internacional de Integración.

LEVINAS, Emmanuel. 2002. Totalidad e infinito. Salamanca: Sígueme.

---. 1987. De otro modo que ser o más allá de la esencia. Salamanca: Sígueme. 
LEWIN, Boleslao. 1972. La rebelión de Tupac Amaru. La Habana: Editorial de Ciencias Sociales.

MIRANDA LUIZAGA, Jorge y Viviana Del Carpio. 2006. “Fundamentos de las espiritualidades panandinas". Teología Andina. Tomo I. La Paz: ISEAT y Plural Editores. 21-36.

PATZI, Félix. 2005. "Rebelión indígena contra la colonialidad y la transnacionalización de la economía: Triunfos y vicisitudes del movimiento indígena desde 2000 a 2003". Ya es Otro Tiempo el Presente, Forrest Hylton et al, eds. La Paz: Muela del Diablo. 199-279.

QUIJANO, Aníbal. 2000. "Colonialidad del poder y clasificación social”. Journal of World-System Research. Vol. XI/2 (Summer/Fall): 342-386.

RENGIFO VÁSQUEZ, Grimaldo. 1996. El ayllu. Manuscrito inédito.

---. 1995. La crianza recíproca: biodiversidad en los Andes.

[http://www.grain.org/es/article/entries/805-la-crianza-reciprocabiodiversidad-en-los- andes] página descargada el 15 de diciembre 2012.

---. 1991. "Prueba y diálogo en la cultura andina: experimentación y extensión en Occidente moderno". Cultura Andina Agrocéntrica. Lima: PRATEC. 209-241.

---. y Eduardo Grillo. 2001. "Criar la vida y dejarse criar”. Suma Qamaña. La comprensión indígena de la Buena Vida. Javier Medina, ed. La Paz: GTZ-FAM. 51-59.

SAAVEDRA, Bautista. 1955 [1903]. El ayllu (Estudio sociológico). La Paz: Editorial Gisbert

SAGRADA BIBLIA. 1968. Nacar-Colunga, trads. Madrid: Biblioteca de Autores Cristianos.

THOMSON, Sinclair. 2007. Cuando sólo reinasen los indios. La Paz: Muela del Diablo.

THOA (Taller de Historia Oral Andina) 1995. Ayllu: pasado y futuro de los pueblos originarios. La Paz: Aruwiyiri.

TORÁ. 2001. Torat Emmet. Un mensaje de vida. Rabino R. Sigal, trad. Buenos Aires: Keter Torá.

\section{(cc) BY-NC-ND}

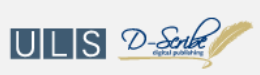

This work is licensed under a Creative Commons AttributionNoncommercial-No Derivative Works 3.0 United States License.

This journal is published by the University Library System of the University of Pittsburgh as part of its D-Scribe Digital Publishing Program, and is cosponsored by the University of Pittsburgh Press. 